Review Article

\title{
Comparison of Diagnosis Accuracy between a Backpropagation Artificial Neural Network Model and Linear Regression in Digestive Disease Patients: an Empirical Research
}

\author{
Wei Wei $\mathbb{D}^{1}$ and Xu Yang $\mathbb{D}^{2}$ \\ ${ }^{1}$ Clinical Epidemiology and Evidence-Based Medical Center, Beijing Friendship Hospital, Capital Medical University, \\ National Clinical Research Center for Digestive Diseases, Beijing 100050, China \\ ${ }^{2}$ School of Computer Science and Technology, Beijing Institute of Technology, Beijing 100081, China
}

Correspondence should be addressed to Xu Yang; yangxu@tsinghua.edu.cn

Received 18 November 2020; Revised 10 December 2020; Accepted 18 February 2021; Published 28 February 2021

Academic Editor: Waqas Haider Bangyal

Copyright (c) 2021 Wei Wei and Xu Yang. This is an open access article distributed under the Creative Commons Attribution License, which permits unrestricted use, distribution, and reproduction in any medium, provided the original work is properly cited.

\begin{abstract}
Introduction. A Noninvasive diagnosis model for digestive diseases is the vital issue for the current clinical research. Our systematic review is aimed at demonstrating diagnosis accuracy between the BP-ANN algorithm and linear regression in digestive disease patients, including their activation function and data structure. Methods. We reported the systematic review according to the PRISMA guidelines. We searched related articles from seven electronic scholarly databases for comparison of the diagnosis accuracy focusing on BP-ANN and linear regression. The characteristics, patient number, input/output marker, diagnosis accuracy, and results/conclusions related to comparison were extracted independently based on inclusion criteria. Results. Nine articles met all the criteria and were enrolled in our review. Of those enrolled articles, the publishing year ranged from 1991 to 2017. The sample size ranged from 42 to 3222 digestive disease patients, and all of the patients showed comparable biomarkers between the BP-ANN algorithm and linear regression. According to our study, 8 literature demonstrated that the BP-ANN model is superior to linear regression in predicting the disease outcome based on AUROC results. One literature reported linear regression to be superior to BP-ANN for the early diagnosis of colorectal cancer. Conclusion. The BP-ANN algorithm and linear regression both had high capacity in fitting the diagnostic model and BP-ANN displayed more prediction accuracy for the noninvasive diagnosis model of digestive diseases. We compared the activation functions and data structure between BP-ANN and linear regression for fitting the diagnosis model, and the data suggested that BP-ANN was a comprehensive recommendation algorithm.
\end{abstract}

\section{Introduction}

Digestive disease involves the tube from the esophagus to the stomach and intestines as well as various organs connected to this tube such as the liver and pancreas, which are very complicated medical situations involving multiple-organ systems and biochemistry, immunology, and pathology mechanisms [1]. Based on the 2015 China Health Statistics Annuals, the twoweek prevalence and chronic disease prevalence of digestive diseases were 15\%o and 24.9\%o, respectively [2]. American Centers for Disease Control and Prevention (CDC) reported almost 60 to 70 million people being affected by all kinds of digestive dis- eases in 2001, and 9.3\% (18.9 million) of noninstitutionalized adults were diagnosed with digestive disorders annually (Summary Health Statistics for US Adults, 2001, NCHS, CDC) [3]. Economists estimated $\$ 912,443,000$ being spent in public hospitals on digestive system diseases in Australia from 2001 to 2002 (AIHW National Hospital Morbidity Database, Australia's Health 2004, AIHW) [4] (https://www.rightdiagnosis .com/d/digest/stats.htm). The five-year survival of most digestive diseases is more than $80 \%$ if patients could be diagnosed or treated at an early stage [5].

In a previous study, many researchers extracted noninvasive biomarkers for constructing diagnosis or a predictive 
model at an early disease stage in digestive disease patients, especially in tumors that have shown a great value for medical practice due to the rapid test and convenient sampling of these biomarkers [6]. WHO (World Health Organization) guidelines recommended that APRI and FIB-4 could be applied in HBV-reduced fibrosis assessment instead of invasive examinations in limited medical resource countries [7]. And the Lok score performed well in diagnosing portal hypertension using transient elastography (TE) [8]. Gurung et al. used AST/ALT (the AST-to-ALT ratio) to elevate in the alcoholic liver disease pattern in patients with hepatitis C who progressed to liver cirrhosis [9]. Lin et al. constructed the noninvasive diagnosis of nonalcoholic fatty liver disease and quantification of liver fat using a new quantitative ultrasound technique [10]. Characteristic information, hematological examination, biochemical detection, endoscopic ultrasonography, and pathology score were used in mathematical modeling to predict the disease outcome accurately [11-14]. A well-designed model can estimate the complicated, undefined relationship between risk factors as input biomarkers and the probability of occurrence of digestive disease as the output variable [15].

In the most common multivariate statistical model for diagnosis or prediction, biomarkers were extracted as dependent variables in order to derive the linear influence relationship between biomarkers and response variables [16-18]. However, these high-dimensional data collected from different visits were complicated for linear regression and collinearity between correlated biomarkers could not be detected or solved in the linear model [19]. A sophisticated artificial neural network (ANN) algorithm, the backpropagation ANN model, was able to construct vague and nonlinear connections between input biomarkers and the target biomarker through the simulation of complicated processing neurons. The correlation between input variables and target data could be learned by the ANN after training several times [20,21]. The ANN model mimicked signal transmission in human brains through a set of processing units which consist of neurons, and these neurons were interconnected via the weight connections which make signal transmission in parallel and series [22-24]. The most representative construction of ANN consisted of three layers [25]. For clinicians and statisticians, the input layer represented the observed biomarkers of serum biochemical and auxiliary examinations $[26,27]$. The output layer was the indicator of clinical outcomes. The processing of ANN was driven by input data, and the decision making was achieved with minimum adjustments by human $[28-30]$. In the modeling process, training data were analyzed and then the decision was made through output neurons when new input variables were put in [31]. In most of the ANN models, the backpropagation (BP) network was the commonly used solution in dealing with the nonlinear relationship between input variables and output variables by constantly adapting the connection weight value between neurons and the error threshold in each layer to make the output variables approximately towards the expected outcome [32-36]. The BP algorithm was based on error gradient descent (Figure 1), which was aimed at finding the minimum error by adjusting weights of connections between neurons in

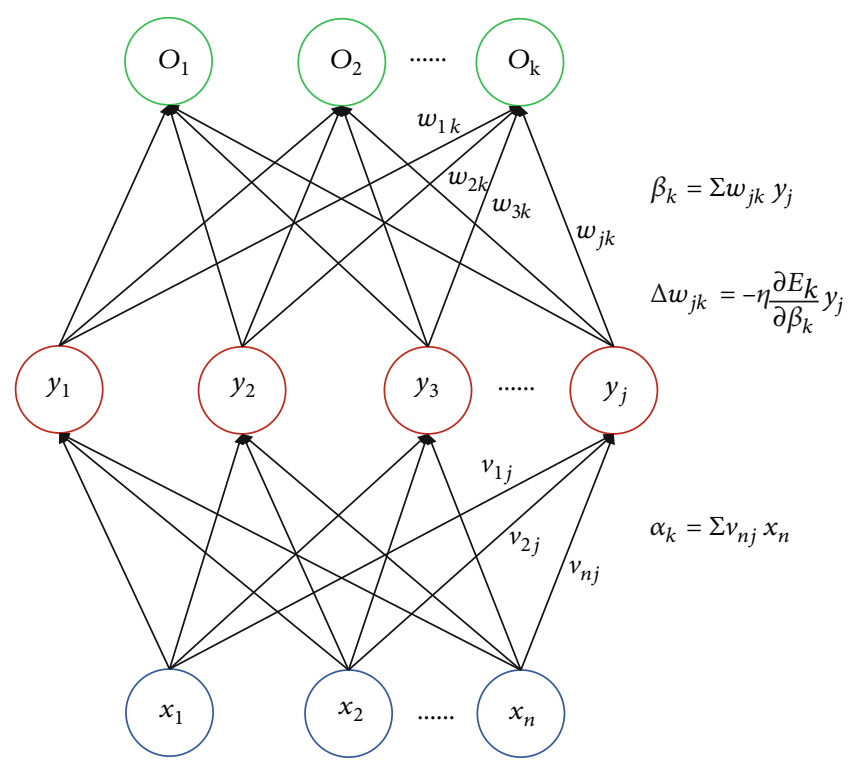

FIgURE 1: The gradient descent of error $E_{k}$ was calculated for the updated parameters in the BP-ANN algorithm process.

the direction of lowest error [37]. The error was estimated from the output variable and backcalculated to converge to the optimum solutions [38].

In linear regression, we assume that the input medical biomarkers and the clinical outcomes would be connected through a nonlinear link function. The BP algorithm demonstrates the modification of weights between synaptic neurons during learning, and the connection would be changed according to an error term computed for neurons throughout each layer. Each computed weight is corrected by the parameters of the activity of the neuron and the error term of the neuron it projects to. We could establish the complicated mathematical model between the input medical biomarkers and each matching output variables. In view of these benefits and limitations, the algorithm with a more accurate calculation and more concise demonstration would be the optimum solution for medical decision. However, the appropriate choice either linear regression or BP-ANN has not been reported in the recent publications and whether the BPANN algorithm is always more accurate versus linear regression is controversial. Therefore, our research will try to discuss the following questions based on a systematic review:

(1) The characteristics of current studies using the BPANN algorithm and linear regression

(2) The correlations between the BP-ANN algorithm and linear regression

(3) Comparison of diagnosis accuracy between the BPANN algorithm and linear regression for digestive diseases

\section{Methods}

2.1. Correlations between the BP-ANN Algorithm and Linear Regression. In respect of linear principal component 
structure data, linear regression could be interpreted as a one-layer perceptron neural structure model, which included input variables and output variables (Figure 2). The input layer transmitted the input clinical biomarkers directly to the output variable through sigmoid function, which would calculate the weight of each input variable in linear regression, that is equal to the regression coefficient using the least square method $[39,40]$.

The activation function is a very important issue because it is the direct bridge between input variables and the clinical outcome, which greatly affect the prediction accuracy. According to the activation function, nonlinearity correlation would be transformed to linear regression, which is an effective solution for calculating the parameters in the hidden layer [41]. Different types of activation functions may lead to different neural network parameters, and the commonly used activation functions include the sigmoid function, tanh function, and Gaussian function [42-44].

$$
\begin{aligned}
h(x) & =\frac{1}{1+e^{-(a x+b)},} \\
\tan h(x) & =\frac{\sin h(x)}{\cos h(x)}, \\
h(x) & =e^{-\left(x-\omega_{i}\right)^{2} / \rho_{i}^{2}} .
\end{aligned}
$$

The input variables were fitted by linear regression before the activation function was applied, as shown in Figure 2, where Figures 2(a) and 2(b) represented the intercept and the coefficient, respectively. In the sigmoid function, variables transformed to the " $s$ " curve and its value is between 0 and 1 . In the tanh function, the value transformed between -1 and 1 . In the Gaussian function, $\omega_{i}$ and $\rho_{i}$ were the center and length, respectively. As seen in equation (1), the activation functions were complex for researchers to determine the optimal function because of the change of parameters; therefore, the machine learning algorithm is used to help optimize and fit an activation function for the neural network [45].

2.2. Error Propagation in BP-ANN and Linear Regression. The linear regression for principal component analysis fitted the straight line which crosses the hidden layer in the neural network, and the next process was to generalize this straight line to a curve. Based on the principal component analysis, the BP-ANN model could fix nonlinear principal component data and the algorithm was backpropagation for mean square error (MSE) and composed of a gradient descent method which was widely used in numerical minimization of a preestablished cost function [38, 46]. According to the gradient trends, the BP model could update parameters between hidden layers and the input layer [47]. Combined with the BP network structure, the process of error propagation started from the output layer as follows:

$$
E=\sum_{k} E_{k}=\sum_{k} \frac{1}{2}\left(d_{k}-o_{k}\right)^{2}
$$

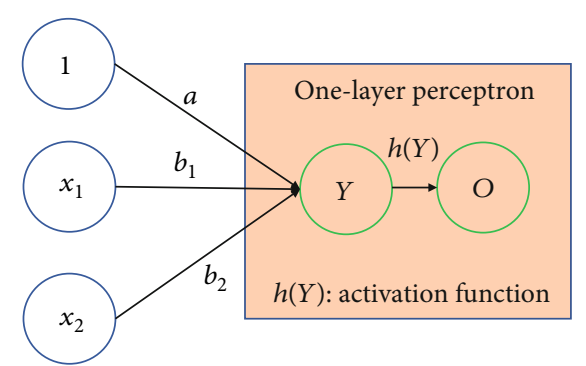

Figure 2: The linear regression algorithm process, which was interpreted as the one-layer perceptron neural structure model $Y$ $=a+b_{1} x_{1}+b_{2} x_{2}$.

where $E$ is the total error and $E_{k}$ is the error for the $k^{\text {th }}$ output neuron, which is the deviation between the actual output $o_{k}$ and expected output $d_{k}$ of the $k^{\text {th }}$ output neuron.

If the above error definition formula is extended to hidden layer neurons, where $y_{j}$ represents the output of the $j^{\text {th }}$ hidden layer neuron and $\omega_{j k}$ represents the weight of the connection between the $j^{\text {th }}$ hidden layer neuron and the $k^{\text {th }}$ output neuron, then

$$
\begin{aligned}
E & =\sum_{k} E_{k}=\frac{1}{2} \sum_{k}\left[d_{k}-o_{k}\right]^{2}=\frac{1}{2} \sum_{k}\left[d_{k}-f\left(\text { net }_{k}\right)\right]^{2} \\
& =\frac{1}{2} \sum_{k}\left[d_{k}-f\left(\sum_{j} w_{j k} y_{j}\right)\right]^{2}
\end{aligned}
$$

where $f$ is the activation function.

If the function extended to input neurons, where $x_{n}$ represents the output of the $n^{\text {th }}$ input neuron and $v_{n j}$ represents the weight of the connections between the $n^{\text {th }}$ input neuron and the $j^{\text {th }}$ hidden layer neuron, then

$$
\begin{aligned}
E & =\frac{1}{2} \sum_{k}\left\{d_{k}-f\left[\sum_{j} w_{j k} f\left(\text { net }_{j}\right)\right]\right\}^{2} \\
& =\frac{1}{2} \sum_{k}\left\{d_{k}-f\left[\sum_{j} w_{j k} f\left(\sum_{n} v_{n j} x_{n}\right)\right]\right\}^{2} .
\end{aligned}
$$

According to the above formula, the total error $E$ of the network is the function of every connection weight value $\omega_{j k}, v_{n j}$, so the error $E$ can be reduced by adjusting the weight value of connections.

Based on the total error, the optimal weight could be solved by calculating partial derivatives.

$$
\begin{gathered}
\Delta \omega_{j k}=-\eta \frac{\partial E}{\partial w_{j k}}, \\
\Delta v_{n j}=-\eta \frac{\partial E}{\partial v_{n j}} .
\end{gathered}
$$


If we do

$$
\begin{aligned}
& \beta_{k}=\sum \omega_{j k} y_{j}, \\
& \alpha_{n}=\sum v_{n j} x_{n},
\end{aligned}
$$

then, equation (5) could be written as follows:

$$
\begin{gathered}
\Delta \omega_{j k}=-\eta \frac{\partial E}{\partial w_{j k}}=-\eta \frac{\partial E}{\partial \beta_{k}} \frac{\partial \beta_{k}}{\partial w_{j k}}=-\eta \frac{\partial E}{\partial \beta_{k}} y_{j}, \\
\Delta v_{n j}=-\eta \frac{\partial E}{\partial v_{n j}}=-\eta \frac{\partial E}{\partial \alpha_{n}} \frac{\partial \alpha_{n}}{\partial v_{n j}}=-\eta \frac{\partial E}{\partial \alpha_{n}} x_{n} .
\end{gathered}
$$

After each iteration, the weights were adjusted by adding the change $\Delta \omega_{j k}$ or $\Delta v_{n j}$ to the original weights to minimize the total error. A parameter " $\eta$ ", the learning rate, was used to define the weight change along with the gradient descent algorithm. Based on the above formula, the weight change is negative when the gradient is positive and vice versa, which would maintain the solutions towards the least error [39, 48-51].

2.3. Search Strategy for Related Studies. In our study, we searched related articles from the following databases: MEDLINE, Embase, Cochrane Library, Chinese Biomedical Literature Database, Wanfang, and CNKI, covering the publish period between January 1, 1966 and May 1, 2019. The search strategy was as follows: "(digestive disease OR digestive system) AND (linear regression OR logistic regression OR logit model) AND (ANN OR back propagation ANN OR BPANN) AND (prediction OR diagnostic OR diagnosis)." The titles and abstracts of relevant studies were screened based on eligibility criteria and classified to different groups: (1) duplicated, (2) not relevant, and (3) relevant. Full texts of enrolled studies were assessed by Wei and Yang. Our study was carried out and reported following the recommendations of the Preferred Reporting Items for Systematic Reviews and Meta-Analyses (PRISMA statement) [52].

2.4. Selection Criteria for Enrolled Studies. Studies were enrolled if (1) patients were aged from 18 to 65 years and diagnosed with digestive diseases for more than 6 months. Hospital-based or community-based participants were all enrolled; (2) diagnostic or predictive trials were performed compared with linear regression (multiple linear regression, logistic regression, and Poisson regression) and the BP-ANN model simultaneously. The input variables were consistent in linear regression and the BP-ANN model; and (3) outcomes of model accuracy were assessed with following indicators: the area under the receiver operating characteristic curve (AUROC), sensitivity (SEN), specificity (SPE), false-positive rate (FPR), false-negative rate (FNR), and prediction accuracy $=($ no.of true classified patients/no.of all the patients $) * 100 \%$ $=(\mathrm{SEN}+\mathrm{SPE}) /(\mathrm{SEN}+\mathrm{SPE}+\mathrm{FPR}+\mathrm{FNR}) * 100 \%[53]$.

The exclusion criteria were (1) patients who complicated with severe cardiovascular and cerebrovascular disease, (2) patients who have psychological disorder, and (3) patients who suffered malignant digestive tumor and with an expected survival time of less than one year.

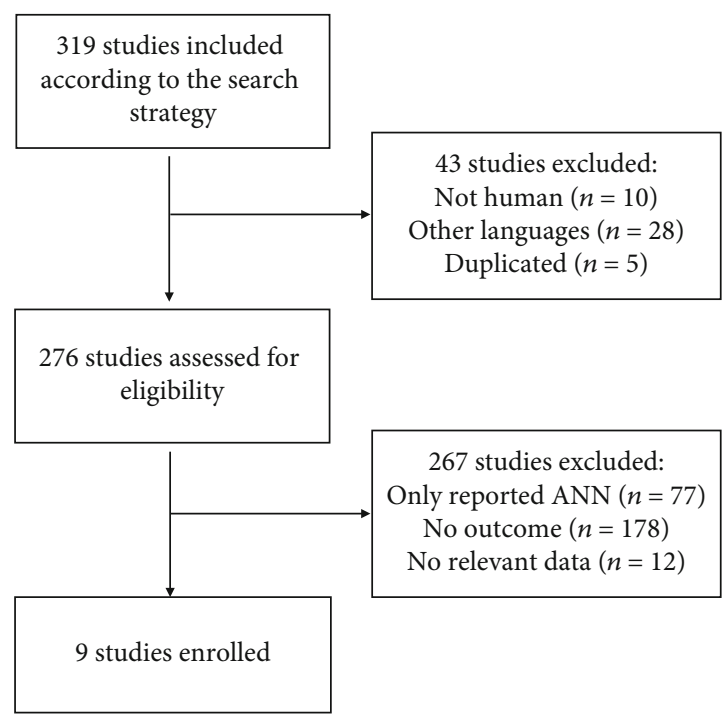

FIgURE 3: Flow chart of literature search and the extraction process.

The methodological quality of enrolled cohort studies was assessed with the Newcastle-Ottawa quality assessment scale, an established composite score from 3 items: (1) representativeness of exposed and nonexposed patients and the ascertainment of exposure, (2) comparability of cohorts on the basis of the study, and (3) assessment of the outcome and the follow-up was long enough for the outcome to occur.

\section{Results and Discussion}

3.1. Characteristics of Included Studies. A total of 319 articles were retrieved from the search strategy, and 43 of them were removed based on screening of titles and abstracts. Two hundred and seventy-six articles were assessed for eligibility and 267 articles were excluded. Nine articles met all the criteria and were enrolled in our review. The flowchart of literature search and the selection process was shown in Figure 3. Of those enrolled articles, the publish year ranged from 1991 to 2017. Seven articles were from China (containing Taiwan Province), one article from Austria, and 1 from Korea. The sample size ranged from 42 to 3222 digestive disease patients, and all of the patients showed comparable biomarkers between the BP-ANN algorithm and linear regression (Table 1).

3.2. Diagnosis Accuracy Comparison between the BP-ANN Algorithm and Linear Regression for Digestive Diseases. According to our systematic review, 8 literature demonstrated that the BP-ANN model is superior to linear regression in predicting the disease outcome based on AUROC results (Table 1). Other researchers [63-66] identically demonstrated that the BP-ANN model had great abilities in information processing, high parallelism related to nonlinearity input variables, generalization, and the fault-tolerant capabilities as the nonparametric algorithm, which is widely used for classification, clustering, regression, and dimensionality reduction in several disease fields. The BP-ANN model was superior to linear regression because of its extraordinary processing ability for dealing with the hidden nonlinear 
TABLE 1: Characteristics of enrolled studies.

\begin{tabular}{|c|c|c|c|c|c|c|}
\hline First author & Country & $\begin{array}{c}\text { Patient } \\
\text { no. }\end{array}$ & Output marker & Input markers & Algorithm & Results or conclusions \\
\hline $\begin{array}{l}\text { Reibnegger, } \\
1991 \text { [54] }\end{array}$ & Austria & 42 & $\begin{array}{c}\text { Different liver disease } \\
(\mathrm{FL}=1, \mathrm{CPH}=2 \text {, and } \\
\mathrm{CAH}=3)\end{array}$ & $\begin{array}{c}\text { Neopterin, AST, ALT, and } \\
\text { AST/ALT ratio }\end{array}$ & $\begin{array}{c}\text { Comparison } \\
\text { with linear } \\
\text { discriminant } \\
\text { analysis and } \\
\text { with CART and } \\
\text { BP-ANN }\end{array}$ & $\begin{array}{l}\text { Compared with the other } \\
\text { two techniques, BP-ANN } \\
\text { showed a unique ability to } \\
\text { detect features hidden in the } \\
\text { input data. }\end{array}$ \\
\hline $\begin{array}{l}\text { Gao, } 2004 \\
{[55]}\end{array}$ & China & 3222 & $\begin{array}{c}\mathrm{DM}(\mathrm{DM}=1 \text {, healthy }= \\
0)\end{array}$ & $\begin{array}{c}\text { Pulse, family history, } \\
\text { nephropathy, waist-to-hip } \\
\text { ratio, hypertension, exercise, } \\
\text { and age }\end{array}$ & $\begin{array}{l}\text { BP-ANN vs. } \\
\text { logistic } \\
\text { regression }\end{array}$ & $\begin{array}{l}\text { BP-ANN could assimilate } \\
\text { more complicated } \\
\text { relationships and is better } \\
\text { than logistic regression. }\end{array}$ \\
\hline $\begin{array}{l}\text { Kim, } 2005 \\
{[56]}\end{array}$ & Korea & 94 & $\begin{array}{l}\text { US images of donor liver } \\
\text { with respect to } \\
\text { macrosteatosis } \\
\text { (moderate or severe } \\
\text { steatosis }=1 \text {, normal or } \\
\text { mild steatosis }=0 \text { ) }\end{array}$ & $\begin{array}{c}\text { ALP, GPT, GOT, } \gamma \text {-GGT, } \\
\text { hepatorenal ratio of } \\
\text { echogenicity, tail area ratio, } \\
\text { and tail length of portal vein } \\
\text { wall echogenicity }\end{array}$ & $\begin{array}{l}\text { BP-ANN vs. } \\
\text { ordinal logistic } \\
\text { regression }\end{array}$ & $\begin{array}{l}\text { The area under ROC curve of } \\
\text { ANN was significantly } \\
\text { greater than that of } \\
\text { radiologists }(P<0.05) \text {. }\end{array}$ \\
\hline $\begin{array}{l}\text { Liew, } 2007 \\
{[57]}\end{array}$ & $\begin{array}{l}\text { China } \\
\text { (Taiwan) }\end{array}$ & 117 & $\begin{array}{c}\text { Gallbladder disease } \\
\text { (with gallstone }=1, \text { no } \\
\text { gallstone }=0 \text { ) }\end{array}$ & $\begin{array}{c}\text { Gender, age, BMI, waist } \\
\text { circumference, hip } \\
\text { circumference, SBP, DBP, } \\
\text { sugar, CHO, TG, UA, AST, } \\
\text { ALT, Alb, WBC, } \\
\text { haemoglobin, MCV, insulin, } \\
\text { hsCRP, total protein, HDL- } \\
\text { C, HbA1C, HOMA, acute } \\
\text { inflammation, chronic } \\
\text { inflammation, eosinophil, } \\
\text { cholesterolosis, cholesterol } \\
\text { polyp, and gastric metaplasia }\end{array}$ & $\begin{array}{l}\text { BP-ANN vs. } \\
\text { logistic } \\
\text { regression }\end{array}$ & $\begin{array}{l}\text { The average correct } \\
\text { classification rate of ANNs } \\
\text { was higher than that of } \\
\text { logistic regression ( } 97.14 \% \\
\text { vs. } 88.2 \%)\end{array}$ \\
\hline $\begin{array}{l}\text { Chuang, } \\
2011[58]\end{array}$ & $\begin{array}{l}\text { China } \\
\text { (Taiwan) }\end{array}$ & 166 & $\begin{array}{c}\text { Liver disease } \\
(\text { diseased }=1, \text { healthy }= \\
0)\end{array}$ & $\begin{array}{l}\text { HBsAg, HBeAg, anti-HBs, } \\
\text { anti-HBe, anti-HBc, anti- } \\
\text { HCV, AST, ALT, TBil, ALB, } \\
\text { ALP, r-GT, AFP, gender, } \\
\text { marriage, blood type, age, } \\
\text { education, occupation, } \\
\text { tattoo, smoking, chewing } \\
\text { betel nut, alcohol, fatigue, } \\
\text { sleep, nap, exercise, } \\
\text { breakfast, vegetables, fruits, } \\
\text { food date mark, food } \\
\text { composition, low salt, } \\
\text { healthy status, weight, } \\
\text { physical discomfort, healthy } \\
\text { examination, acupuncture, } \\
\text { and blood donation }\end{array}$ & $\begin{array}{l}\text { A comparison } \\
\text { of BP-ANN, } \\
\text { CART, logistic } \\
\text { regression, and } \\
\text { DA }\end{array}$ & $\begin{array}{l}\text { BP-ANN was the best model } \\
\text { for liver disease with the } \\
\text { accuracy of } 95 \% \text {. The } \\
\text { accuracy rates of CART, } \\
\text { logistic regression, and DA } \\
\text { were } 91 \%, 86 \% \text {, and } 84 \% \text {, } \\
\text { respectively. }\end{array}$ \\
\hline $\begin{array}{l}\text { Zhang, } 2016 \\
\text { [59] }\end{array}$ & China & 120 & $\begin{array}{l}\text { Pathology diagnosis } \\
\text { results of colorectal } \\
\text { disease (colorectal } \\
\text { patients }=1 \text {, benign }=0 \text { ) }\end{array}$ & $\begin{array}{c}\text { CEA, CA50, HSP60, } \\
\text { CYFRA21-1, TPA, AFP, } \\
\text { CA199, CA242, CA724, } \\
\text { CA125, CA153, and } \\
\text { UGT1A8 }\end{array}$ & $\begin{array}{l}\text { BP-ANN vs. } \\
\text { forward logistic } \\
\text { stepwise } \\
\text { regression vs. } \\
\text { SVM }\end{array}$ & $\begin{array}{l}\text { The AUROC of combined } \\
\text { detection was } 0.988, \text { in } \\
\text { logistic regression. The } \\
\text { detection rate was } 75 \% \text { in the } \\
\text { BP-ANN model. }\end{array}$ \\
\hline $\begin{array}{l}\text { Fei, } 2017 \\
{[60]}\end{array}$ & China & 79 & $\begin{array}{l}\text { PSMVT (positive or } \\
\text { negative) }\end{array}$ & $\begin{array}{l}\text { Age, sex, Hct, PT, FBG, D- } \\
\text { dimer, Ca, TG, AMY, } \\
\text { APACHEII score, and } \\
\text { Ranson score }\end{array}$ & $\begin{array}{l}\text { One-layer BP- } \\
\text { ANN vs. } \\
\text { logistic } \\
\text { regression }\end{array}$ & $\begin{array}{l}\text { The ANN model was more } \\
\text { accurate than logistic } \\
\text { regression in predicting the } \\
\text { occurrence of PSMVT. }\end{array}$ \\
\hline $\begin{array}{l}\mathrm{Ma}, 2017 \\
{[61]}\end{array}$ & China & 575 & $\begin{array}{l}\text { BMI (overweight }=1 \text {, } \\
\text { healthy }=0 \text { ) }\end{array}$ & $\begin{array}{l}\text { Weight, height, age, fs-TG, } \\
\text { fs-TC, and fs-GLU }\end{array}$ & $\begin{array}{l}\text { BP-ANN vs. } \\
\text { multiple linear } \\
\text { regression }\end{array}$ & $\begin{array}{l}\text { The BP-ANN models } \\
\text { achieved higher prediction } \\
\text { accuracy than linear } \\
\text { regression. }\end{array}$ \\
\hline
\end{tabular}


TABLE 1: Continued.

\begin{tabular}{|c|c|c|c|c|c|c|}
\hline First author & Country & $\begin{array}{c}\text { Patient } \\
\text { no. }\end{array}$ & Output marker & Input markers & Algorithm & Results or conclusions \\
\hline $\begin{array}{l}\text { Shao, } 2017 \\
{[62]}\end{array}$ & China & 288 & Inoperable HCA & $\begin{array}{l}\text { Sex, age, stage, diameter, liver } \\
\text { metastasis, ascites, prior } \\
\text { abdominal surgery, } \\
\text { comorbidity, and bismuth } \\
\text { stage }\end{array}$ & $\begin{array}{l}\text { BP-ANN vs. } \\
\text { logistic } \\
\text { regression } \\
\text { model }\end{array}$ & $\begin{array}{l}\text { The AUC of the BP-ANN } \\
\text { had larger AUC than the } \\
\text { multivariate logistic } \\
\text { regression model } \\
(P=0.02142) .\end{array}$ \\
\hline
\end{tabular}

relationship between input markers and the clinical outcome, which might be ignored by linear regression and statisticians [67-70].

The self-learning and adaptive capacity of BP-ANN is one of the advantages compared with linear regression [71]. In the two-phase process of training neural networks, the reasonable rules between input and output variables could be automatically extracted through backpropagation self-learning, which would be remembered and then translated to the neuron weights in networks based on adaptive capacity [72-76]. The self-learning phases were commonly repeated for more than 10000 times; the weighted values and error threshold tended to be optimized until the model converges [77]. For most clinicians, a well estimated noninvasive diagnostic model or disease outcome classifier would help to make a correct decision instead of invasive detection. Based on these clinical demands, the BP-ANN training process had the ability to deal with unrecognized confounders for constructing the more accurate classifier, which could transfer training achievements to the unknown information between input variables and clinical outcomes [78-80].

Meanwhile, due to the current availability of big data in multicenter clinical research, enhanced computing power with graphics processing units, and new algorithms to fit neural networks, a computer-aided system could handle thousands of input variables as well as recognize hidden information and made more accurate decisions than fitting in linear regression [81].

The extrapolation performance of the BP-ANN model was a noteworthy development; from the mathematical perspective, BP-ANN could achieve an optimal method that locally searches the global solutions [82-84]. In this process, the weights between neurons were adjusted gradually according to the direction of local improvement, which may enable the algorithm and the weights into local extremum convergence [85]. In addition, BP-ANN was sensitive to initial weights in the network and different initialized networks tend to converge to the related local minimum and many researchers constructed different models after training [79, 86-89].

One literature reported linear regression to be superior to BP-ANN for the early diagnosis of colorectal cancer, in which the input variables were only serum tumor markers, including CEA, CA199, CA242, et al. [46]. Compared with the BP-ANN diagnosis model, logistic regression analysis showed better results, which was related to a multiparameter used within a certain range [90]. The success of the linear regression method in the development of the interpretative and diagnosis model algorithm required the representative and homogeneous of the data structure, elimination of redundancy input variables, appropriate ratio between the number of input variables and the output variables, and accomplishment of strict validation procedures [91-93].

\section{Conclusions}

The noninvasive diagnostic model is one of the vital issues for digestive clinicians and statisticians. Based on our systematic review, the BP-ANN algorithm and linear regression had high capacity in fitting the diagnostic model and BP-ANN displayed more prediction accuracy in most of enrolled studies. To elaborate the situations, we compared the activation functions and data structure between BP-ANN and linear regression for fitting the diagnosis model and the data suggested that BPANN was a comprehensive recommendation algorithm.

Based on the traditional three-layer neural networks, statisticians have developed a set of deep learning algorithms with different approaches [94]. Deep learning neural networks (DNN) have extended the depth of layers to four or more layers and performed better than traditional neural networks in diagnosis and prediction when the neural network construction become complex [95-97]. Hinton et al. used an unsupervised restricted Boltzmann machine with deep layers in neural architecture to overcome the limitations of local minimum and overfitting [98]. Also, the convolutional neural network $(\mathrm{CNN})$ encompasses a multilayer of computational connections with minimized processing which performed well in recent research [99-102]. Therefore, further research may focus on the correlations between the traditional neural network and other machine learning algorithms, including deep learning neural networks, convolutional neural networks, and support vector machine method, to select the appropriate algorithm for digestive diseases.

\section{Abbreviations}

ANN: Artificial neural network

AUROC: Area under the receiver operating characteristic curve

BP: Backpropagation

CAH: Chronic aggressive non-A, non-B hepatitis

CART: Classification and regression tree

CDC: American Centers for Disease Control and Prevention

$\mathrm{CPH} \quad$ Chronic persistent non-A, non-B hepatitis 


$\begin{array}{ll}\text { DA: } & \text { Discriminatory analysis } \\ \text { DM: } & \text { Diabetes mellitus } \\ \text { FL: } & \text { Fatty liver } \\ \text { FNR: } & \text { False-negative rate } \\ \text { FPR: } & \text { False-positive rate } \\ \text { HCA: } & \text { Hilar cholangiocarcinoma } \\ \text { MSE: } & \text { Mean square error } \\ \text { PSMVT: } & \text { Portosplenomesenteric venous thrombosis } \\ \text { PPU: } & \text { Perforated peptic ulcer } \\ \text { SEN: } & \text { Sensitivity } \\ \text { SPE: } & \text { Specificity } \\ \text { TE: } & \text { Transient elastography } \\ \text { WHO: } & \text { World Health Organization. }\end{array}$

\section{Data Availability}

The data used to support this study could be found in listed references.

\section{Disclosure}

The funders had no role in the design of the study; in the collection, analyses, or interpretation of data; in the writing of the manuscript; or in the decision to publish the results.

\section{Conflicts of Interest}

The authors declare no conflict of interest.

\section{Authors' Contributions}

All authors have contributed significantly to the manuscript and all authors agree with the content. Conception/design was done by Xu Yang. Data collection and manuscript writing was done by Wei Wei and Xu Yang. Reviewing of the manuscript was done by Xu Yang.

\section{Acknowledgments}

This research was supported by grants from the National Nature Science Foundation of China (under Grant no. 91846303), Beijing Municipal Administration of Hospitals Incubating Program (no. PX2018071), and Research Foundation of Beijing Friendship Hospital, Capital Medical University (no. yyqdkt2015-15).

\section{References}

[1] K. Ikuta, H. Ito, K. Takahashi, S. Masaki, M. Terauchi, and Y. Suzuki, "Safety and efficacy of intravenous ferric carboxymaltose in Japanese patients with iron-deficiency anemia caused by digestive diseases: an open-label, single-arm study," International Journal of Hematology, vol. 109, no. 1, pp. 50-58, 2019.

[2] National Health Commission of the People's Republic of China, China Health Statistics Annuals, 2015.

[3] Centers for Disease Control and Prevention, Summary Health Statistics for US Adults: National Health Interview Survey, 2001.
[4] Australia Institute of Health and Welfare, National Hospital Morbidity Database, Australia's Health, 2004.

[5] T. W. Jun, M. L. Yeh, J. D. Yang et al., "More advanced disease and worse survival in cryptogenic compared to viral hepatocellular carcinoma," Liver International, vol. 38, no. 5, pp. 895-902, 2018.

[6] J. Jung, Y. Jung, E. J. Bang et al., "Noninvasive diagnosis and evaluation of curative surgery for gastric cancer by using NMR-based metabolomic profiling," Annals of Surgical Oncology, vol. 21, pp. S736-S742, 2014.

[7] Guidelines for the Screening, Cand Treatment of Persons with Hepatitis B Infection, World Health Organization, Geneva, 2015.

[8] L. Castera, M. Pinzani, and J. Bosch, "Non invasive evaluation of portal hypertension using transient elastography," Journal of Hepatology, vol. 56, no. 3, pp. 696-703, 2012.

[9] R. B. Gurung, B. Purbe, P. Gyawali, and P. Risal, "The ratio of aspartate aminotransferase to alanine aminotransferase (AST/ALT): the correlation of value with underlying severity of alcoholic liver disease," Kathmandu University Medical Journal, vol. 11, pp. 233-236, 2013.

[10] S. C. Lin, E. Heba, T. Wolfson et al., "Noninvasive diagnosis of nonalcoholic fatty liver disease and quantification of liver fat using a new quantitative ultrasound technique," Clinical Gastroenterology and Hepatology, vol. 13, no. 7, pp. 13371345.e6, 2015.

[11] B. M. Ozyildirim and M. Avci, "Generalized classifier neural network,” Neural Networks, vol. 39, pp. 18-26, 2013.

[12] H. Y. Li, J. Lam, and K. C. Cheung, "Passivity criteria for continuous-time neural networks with mixed time-varying delays," Applied Mathematics and Computation, vol. 218, no. 22, pp. 11062-11074, 2012.

[13] R. Rakkiyappan, E. Udhaya Kumari, A. Chandrasekar, and R. Krishnasamy, "Synchronization and periodicity of coupled inertial memristive neural networks with supremums," Neurocomputing, vol. 214, pp. 739-749, 2016.

[14] X. Yang, J. Cao, and W. Yu, "Exponential synchronization of memristive Cohen Grossberg neural networks with mixed delays," Cognitive Neurodynamics, vol. 8, no. 3, pp. 239-249, 2014.

[15] D. Ansari, J. Nilsson, R. Andersson, S. Regner, B. Tingstedt, and B. Andersson, "Artificial neural networks predict survival from pancreatic cancer after radical surgery," American Journal of Surgery, vol. 205, no. 1, pp. 1-7, 2013.

[16] S. Wen, X. Huang, R. F. Frankowski, J. N. Cormier, and P. Pisters, "A Bayesian multivariate joint frailty model for disease recurrences and survival," Statistics in Medicine, vol. 35, no. 26, pp. 4794-4812, 2016.

[17] Y. C. Hagar, D. J. Harvey, and L. A. Beckett, "A multivariate cure model for left-censored and right-censored data with application to colorectal cancer screening patterns," Statistics in Medicine, vol. 35, no. 19, pp. 3347-3367, 2016.

[18] D. B. McArtor, B. D. Lin, J. J. Hottenga, D. I. Boomsma, G. Willemsen, and G. H. Lubke, "Using a multivariate model to assess the interactive effects of demographics and lifestyle on the hematological profile," Biomarkers in Medicine, vol. 11, no. 6, pp. 427-438, 2017.

[19] S. S. Cross, R. F. Harrison, and R. L. Kennedy, "Introduction to neural networks," The Lancet, vol. 346, no. 8982, pp. 10751079, 1995.

[20] W. Tian, F. Meng, L. Liu, Y. Li, and F. Wang, "Lifetime prediction for organic coating under alternating hydrostatic 
pressure by artificial neural network," Scientific Reports, vol. 7, no. 1, p. 40827, 2017.

[21] F. Demirci, P. Akan, T. Kume, A. R. Sisman, Z. Erbayraktar, and S. Sevinc, "Artificial neural network approach in laboratory test reporting: learning algorithms," American Journal of Clinical Pathology, vol. 146, no. 2, pp. 227-237, 2016.

[22] D. Taylor, A. Harrison, and D. Powers, “An artificial neural network system to identify alleles in reference electropherograms," Forensic Science International. Genetics, vol. 30, pp. 114-126, 2017.

[23] L. A. Peixoto, L. L. Bhering, and C. D. Cruz, "Artificial neural networks reveal efficiency in genetic value prediction," Genetics and Molecular Research, vol. 14, no. 2, pp. 6796-6807, 2015.

[24] Y. Fei and W. Q. Li, "Improve artificial neural network for medical analysis, diagnosis and prediction," Journal of Critical Care, vol. 40, p. 293, 2017.

[25] D. Itchhaporia, P. B. Snow, R. J. Almassy, and W. J. Oetgen, "Artificial neural networks: current status in cardiovascular medicine," Journal of the American College of Cardiology, vol. 28, no. 2, pp. 515-521, 1996.

[26] A. Liparini, S. Carvalho, and J. C. Belchior, "Analysis of the applicability of artificial neural networks for studying blood plasma: determination of magnesium ion concentration as a case study," Clinical Chemistry and Laboratory Medicine, vol. 43, no. 9, pp. 939-946, 2005.

[27] H. A. Abbass, "An evolutionary artificial neural networks approach for breast cancer diagnosis," Artificial Intelligence in Medicine, vol. 25, no. 3, pp. 265-281, 2002.

[28] J. G. Lee, S. Jun, Y. W. Cho et al., "Deep learning in medical imaging: general overview," Korean Journal of Radiology, vol. 18, no. 4, pp. 570-584, 2017.

[29] T. Zheng, W. Xie, L. Xu et al., "A machine learning-based framework to identify type 2 diabetes through electronic health records," International Journal of Medical Informatics, vol. 97, pp. 120-127, 2017.

[30] B. van Ginneken, "Fifty years of computer analysis in chest imaging: rule-based, machine learning, deep learning," Radiological Physics and Technology, vol. 10, no. 1, pp. 2332, 2017.

[31] T. Yarkoni and J. Westfall, "Choosing prediction over explanation in psychology: lessons from machine learning," Perspectives on Psychological Science, vol. 12, no. 6, pp. 1100$1122,2017$.

[32] J. Cao, H. Cui, H. Shi, and L. Jiao, "Big data: a parallel particle swarm optimization-back-propagation neural network algorithm based on MapReduce," PLoS One, vol. 11, no. 6, article e0157551, 2016.

[33] D. Rotermund and K. R. Pawelzik, "Back-propagation learning in deep spike-by-spike networks," Frontiers in Computational Neuroscience, vol. 13, pp. 13-55, 2019.

[34] E. R. Rene, M. E. López, J. H. Kim, and H. S. Park, "Back propagation neural network model for predicting the performance of immobilized cell biofilters handling gas-phase hydrogen sulphide and ammonia," BioMed Research International, vol. 2013, Article ID 463401, 9 pages, 2013.

[35] D. Carlucci, P. Renna, and G. Schiuma, "Evaluating service quality dimensions as antecedents to outpatient satisfaction using back propagation neural network," Health Care Management Science, vol. 16, no. 1, pp. 37-44, 2013.

[36] C. Wu and S. Shivakumar, "Back-propagation and counterpropagation neural networks for phylogenetic classification of ribosomal RNA sequences," Nucleic Acids Research, vol. 22, no. 20, pp. 4291-4299, 1994.

[37] R. Gan, X. Chen, Y. Yan, and D. Huang, "Application of a hybrid method combining grey model and back propagation artificial neural networks to forecast hepatitis B in China," Computational and Mathematical Methods in Medicine, vol. 2015, Article ID 328273, 2015.

[38] J. Yu, Q. Pan, J. Yang et al., "Correlations of complete blood count with alanine and aspartate transaminase in Chinese subjects and prediction based on back-propagation artificial neural network (BP-ANN)," Medical Science Monitor, vol. 23, pp. 3001-3009, 2017.

[39] H. A. Soodi and A. M. Vural, "STATCOM estimation using back-propagation, PSO, shuffled frog leap algorithm, and genetic algorithm based neural networks," Computational Intelligence and Neuroscience, vol. 26, 17 pages, 2018.

[40] S. Chatterjee, S. Sarkar, S. Hore, N. Dey, A. S. Ashour, and V. E. Balas, "Particle swarm optimization trained neural network for structural failure prediction of multistoried RC buildings," Neural Computing and Applications, vol. 28, no. 8, pp. 2005-2016, 2017.

[41] Ö. F. Ertuğrul, "A novel type of activation function in artificial neural networks: trained activation function," Neural Networks, vol. 99, pp. 148-157, 2018.

[42] K. Eckle and J. Schmidt-Hieber, "A comparison of deep networks with ReLU activation function and linear spline- type methods," Neural Networks, vol. 110, pp. 232-242, 2019.

[43] N. A. Mohammed, M. Solaiman, and M. H. Aly, "Design and performance evaluation of a dispersion compensation unit using several chirping functions in a tanh apodized FBG and comparison with dispersion compensation fiber," Applied Optics, vol. 53, pp. 239-247, 2014.

[44] P. Liu, Z. G. Zeng, and J. Wang, "Complete stability of delayed recurrent neural networks with Gaussian activation functions," Neural Networks, vol. 85, pp. 21-32, 2017.

[45] E. J. M. Barbosa Jr., M. Lanclus, W. Vos et al., "Machine learning algorithms utilizing quantitative CT features may predict eventual onset of bronchiolitis obliterans syndrome after lung transplantation," Academic Radiology, vol. 25, no. 9, pp. 1201-1212, 2018.

[46] X. Leng, J. Wang, H. Ji et al., "Prediction of size-fractionated airborne particle-bound metals using MLR, BP- ANN and SVM analyses," Chemosphere, vol. 180, pp. 513-522, 2017.

[47] B. B. Alagoz, G. Kavuran, A. Ates, and C. Yeroglu, "Reference-shaping adaptive control by using gradient descent optimizers," PLoS One, vol. 12, no. 11, article e0188527, 2017.

[48] D. J. Sargent, "Comparison of artificial neural networks with other statistical approaches," Cancer, vol. 91, no. S8, pp. 1636-1642, 2001

[49] J. Luo, R. Ren, and K. Guo, "The deformation monitoring of foundation pit by back propagation neural network and genetic algorithm and its application in geotechnical engineering," PLoS One, vol. 15, no. 7, article e0233398, 2020.

[50] M. Malathi and P. Sinthia, "MRI brain tumour segmentation using hybrid clustering and classification by back propagation algorithm," Asian Pacific Journal of Cancer Prevention, vol. 19, pp. 3257-3263, 2018.

[51] P. Dosset, P. Rassam, L. Fernandez et al., "Automatic detection of diffusion modes within biological membranes using back-propagation neural network," BMC Bioinformatics, vol. 17, no. 1, pp. 197-208, 2016. 
[52] D. Moher, A. Liberati, J. Tetzlaff, D. G. Altman, and for the PRISMA Group, "preferred reporting items for systematic reviews and meta-analyses: the PRISMA statement," $B M J$, vol. 339, no. 1, p. b2535, 2009.

[53] A. M. Granados Sánchez and J. F. Orejuela Zapata, "Diagnosis of mesial temporal sclerosis: sensitivity, specificity and predictive values of the quantitative analysis of magnetic resonance imaging," The Neuroradiology Journal, vol. 31, no. 1, pp. 50-59, 2018.

[54] G. Reibnegger, G. Weiss, G. W. Felmayer, G. Judmaier, and H. Wachter, "Neural networks as a tool for utilizing laboratory information: comparison with linear discriminant analysis and with classification and regression trees," Medical Science, vol. 88, pp. 11426-11430, 1991.

[55] W. Gao, S. Y. Wang, Z. N. Wang, L. Y. Shi, and F. X. Dong, "Study on the application of artificial neural network in analysing the risk factors of diabetes mellitus," Journal of Clinical Epidemiology, vol. 25, pp. 715-718, 2004.

[56] S. H. Kim, J. M. Lee, J. H. Kim et al., “Appropriateness of a donor liver with respect to macrosteatosis: application of artificial neural networks to US images-initial experience," Radiology, vol. 234, no. 3, pp. 793-803, 2005.

[57] P. L. Liew, Y. C. Lee, Y. C. Lin et al., "Comparison of artificial neural networks with logistic regression in prediction of gallbladder disease among obese patients," Digestive and Liver Disease, vol. 39, no. 4, pp. 356-362, 2007.

[58] C. L. Chuang, "Case-based reasoning support for liver disease diagnosis," Artificial Intelligence in Medicine, vol. 53, no. 1, pp. 15-23, 2011.

[59] B. Zhang, X. L. Liang, H. Y. Gao, L. S. Ye, and Y. G. Wang, "Models of logistic regression analysis, support vector machine, and back-propagation neural network based on serum tumor markers in colorectal cancer diagnosis," Genetics and Molecular Research, vol. 15, pp. 1-10, 2016.

[60] Y. Fei, J. Hu, W. Q. Li, W. Wang, and G. Q. Zong, “Artificial neural networks predict the incidence of portosplenomesenteric venous thrombosis in patients with acute pancreatitis," Journal of Thrombosis and Haemostasis, vol. 15, no. 3, pp. 439-445, 2017.

[61] J. Ma, J. Yu, G. S. Hao et al., "Assessment of triglyceride and cholesterol in overweight people based on multiple linear regression and artificial intelligence model," Lipids in Health and Disease, vol. 16, no. 1, pp. 42-48, 2017.

[62] F. Shao, Q. Huang, C. Wang, L. J. Qiu, Y. G. Hu, and S. Y. Zha, "Artificial neural networking model for the prediction of early occlusion of bilateral plastic stent placement for inoperable Hilar cholangiocarcinoma," Surgical Laparoscopy, Endoscopy \& Percutaneous Techniques, vol. 28, pp. e54-e58, 2017.

[63] C. Ventura, D. A. Latino, and F. Martins, "Comparison of multiple linear regressions and neural networks based QSAR models for the design of new antitubercular compounds," European Journal of Medicinal Chemistry, vol. 70, pp. 831845, 2013.

[64] P. M. Sathe and J. Venitz, "Comparison of neural network and multiple linear regression as dissolution predictors," Drug Development and Industrial Pharmacy, vol. 29, no. 3, pp. 349-355, 2003.

[65] A. J. C. C. Lins, M. T. C. Muniz, A. N. M. Garcia, A. V. Gomes, R. M. Cabral, and C. J. A. Bastos-Filho, "Using artificial neural networks to select the parameters for the prognostic of mild cognitive impairment and dementia in elderly individuals," Computer Methods and Programs in Biomedicine, vol. 152, pp. 93-104, 2017.

[66] C. C. Hsu, J. Lin, and C. K. Chao, "Comparison of multiple linear regression and artificial neural network in developing the objective functions of the orthopaedic screws," Computer Methods and Programs in Biomedicine, vol. 104, no. 3, pp. 341-348, 2011.

[67] F. Gharagheizi, A. Eslamimanesh, A. H. Mohammadi, and D. Richon, "Determination of critical properties and acentric factors of pure compounds using the artificial neural network group contribution algorithm," Journal of Chemical \& Engineering Data, vol. 56, no. 5, pp. 2460-2476, 2011.

[68] J. Wang, F. Wang, Y. Liu et al., "Multiple linear regression and artificial neural network to predict blood glucose in overweight patients," Experimental and Clinical Endocrinology \& Diabetes, vol. 124, no. 1, pp. 34-38, 2016.

[69] A. Ehret, D. Hochstuhl, D. Gianola, and G. Thaller, "Application of neural networks with back-propagation to genomeenabled prediction of complex traits in Holstein-Friesian and German Fleckvieh cattle," Genetics, Selection, Evolution, vol. 47, no. 1, p. 22, 2015.

[70] R. Dong and G. Zhao, "Predicting in vitro rumen VFA production using CNCPS carbohydrate fractions with multiple linear models and artificial neural networks," PLoS One, vol. 9, no. 12, article e116290, 2014.

[71] P. Cognigni, J. Felsenberg, and S. Waddell, "Do the right thing: neural network mechanisms of memory formation, expression and update in _Drosophila_," Current Opinion in Neurobiology, vol. 49, pp. 51-58, 2018.

[72] T. H. Teng, A. H. Tan, and J. M. Zurada, "Self-organizing neural networks integrating domain knowledge and reinforcement learning," IEEE Trans Neural Netw Learn Syst, vol. 26, no. 5, pp. 889-902, 2015.

[73] J. Chrol-Cannon and Y. Jin, "Computational modeling of neural plasticity for self-organization of neural networks," Biosystems, vol. 125, pp. 43-54, 2014.

[74] X. Yang and H. He, "Self-learning robust optimal control for continuous-time nonlinear systems with mismatched disturbances," Neural Networks, vol. 99, pp. 19-30, 2018.

[75] W. Zhang, "Pattern classification and recognition of invertebrate functional groups using self-organizing neural networks," Environmental Monitoring and Assessment, vol. 130, no. 1-3, pp. 415-422, 2007.

[76] J. K. Liu and D. V. Buonomano, "Embedding multiple trajectories in simulated recurrent neural networks in a selforganizing manner," The Journal of Neuroscience, vol. 29, no. 42, pp. 13172-13181, 2009.

[77] J. M. Bos, Z. I. Attia, D. E. Albert, P. A. Noseworthy, P. A. Friedman, and M. J. Ackerman, "Use of Artificial Intelligence and Deep Neural Networks in Evaluation of Patients With Electrocardiographically Concealed Long QT Syndrome From the Surface 12-Lead Electrocardiogram," JAMA Cardiology, vol. 10, 2021.

[78] H. C. Lee, S. B. Yoon, S. M. Yang et al., "Prediction of acute kidney injury after liver transplantation: machine learning approaches vs logistic regression model," Journal of clinical medicine, vol. 7, no. 11, pp. 428-439, 2018.

[79] S. C. Chen, H. W. Chiu, C. C. Chen, L. C. Woung, and C. M. Lo, "A novel machine learning algorithm to automatically predict visual outcomes in intravitreal ranibizumab-treated 
patients with diabetic macular edema," Journal of Clinical Medicine, vol. 7, no. 12, pp. 475-483, 2018.

[80] S. M. Siniscalchi and V. M. Salerno, "Adaptation to new microphones using artificial neural networks with trainable activation functions," IEEE Transactions on Neural Networks and Learning Systems, vol. 28, pp. 1959-1965, 2016.

[81] Y. J. Choi, J. H. Baek, H. S. Park et al., “A computer-aided diagnosis system using artificial intelligence for the diagnosis and characterization of thyroid nodules on ultrasound: initial clinical assessment," Thyroid, vol. 27, no. 4, pp. 546-552, 2017.

[82] I. Sutskever, J. Martens, G. Dahl, and G. Hinton, "On the importance of initialization and momentum in deep learning," Proceedings of Machine Learning Research, vol. 28, pp. 1139-1147, 2013.

[83] P. Hamet and J. Tremblay, "Artificial intelligence in medicine,” Metabolism, vol. 69, pp. S36-S40, 2017.

[84] A. N. Ramesh, C. Kambhampati, J. R. T. Monson, and P. J. Drew, "Artificial intelligence in medicine," Annals of the Royal College of Surgeons of England, vol. 86, no. 5, pp. 334-338, 2004.

[85] D. B. Neill, "Using artificial intelligence to improve hospital inpatient care," IEEE Intelligent Systems, vol. 28, no. 2, pp. 92-95, 2013.

[86] T. Ho, H. Nguyen, T. Vuong, Q. Dam, H. Pham, and Q. Vuong, "Exploring Vietnamese co-authorship patterns in social sciences with basic network measures of 2008-2017 Scopus data," F1000Research, vol. 6, p. 1559, 2017.

[87] S. Lu, X. Qiu, J. Shi et al., "A pathological brain detection system based on extreme learning machine optimized by bat algorithm," CNS \& Neurological Disorders Drug Targets, vol. 16, no. 1, pp. 23-29, 2017.

[88] M. Bataineh and T. Marler, "Neural network for regression problems with reduced training sets," Neural Networks, vol. 95, pp. 1-9, 2017.

[89] S. Özden, B. Saylam, and M. Tez, "Is artificial neural network an ideal modelling technique?," Journal of Critical Care, vol. 40, p. 292, 2017.

[90] B. X. Tran, G. T. Vu, G. H. Ha et al., "Global evolution of research in artificial intelligence in health and medicine: a bibliometric study," Journal of Clinical Medicine, vol. 8, no. 3, p. 360, 2019.

[91] T. R. Frasier, "A note on the use of multiple linear regression in molecular ecology," Molecular Ecology Resources, vol. 16, no. 2, pp. 382-387, 2016.

[92] J. Li, C. Yen, D. Liaw et al., "PTEN, a putative protein tyrosine phosphatase gene mutated in human brain, breast, and prostate cancer," Science, vol. 275, no. 5308, pp. 1943-1947, 1997.

[93] P. Barmpalexis, A. Karagianni, G. Karasavvaides, and K. Kachrimanis, "Comparison of multi-linear regression, particle swarm optimization artificial neural networks and genetic programming in the development of mini-tablets," International Journal of Pharmaceutics, vol. 551, no. 1-2, pp. 166-176, 2018.

[94] S. Min, B. Lee, and S. Yoon, "Deep learning in bioinformatics," Briefings in Bioinformatics, vol. 18, no. 5, pp. 851-869, 2017.

[95] P. Mamoshina, A. Vieira, E. Putin, and A. Zhavoronkov, "Applications of deep learning in biomedicine," Molecular Pharmaceutics, vol. 13, no. 5, pp. 1445-1454, 2016.
[96] X. Wang, W. Yang, J. Weinreb et al., "Searching for prostate cancer by fully automated magnetic resonance imaging classification: deep learning versus non-deep learning," Scientific Reports, vol. 7, no. 1, p. 15415, 2017.

[97] E. Hoppe, G. Körzdörfer, T. Würfl et al., "Deep learning for magnetic resonance fingerprinting: a new approach for predicting quantitative parameter values from time series," Studies in Health Technology and Informatics, vol. 243, pp. 202206, 2017.

[98] G. E. Hinton, S. Osindero, and Y. W. Teh, “A fast learning algorithm for deep belief nets," Neural Computation, vol. 18, no. 7, pp. 1527-1554, 2006.

[99] H. Sharma, N. Zerbe, I. Klempert, O. Hellwich, and P. Hufnagl, "Deep convolutional neural networks for automatic classification of gastric carcinoma using whole slide images in digital histopathology," Computerized Medical Imaging and Graphics, vol. 61, pp. 2-13, 2017.

[100] U. R. Acharya, S. L. Oh, Y. Hagiwara et al., "A deep convolutional neural network model to classify heartbeats," Computers in Biology and Medicine, vol. 89, pp. 389-396, 2017.

[101] C. Wachinger, M. Reuter, and T. Klein, "DeepNAT: deep convolutional neural network for segmenting neuroanatomy," NeuroImage, vol. 170, pp. 434-445, 2018.

[102] M. H. Hsieh, L. M. Sun, C. L. Lin et al., "Development of a prediction model for colorectal cancer among patients with type 2 diabetes mellitus using a deep neural network," Journal of Clinical Medicine, vol. 7, no. 9, pp. 277-286, 2018. 